\title{
"Que ninguem supporá que eu ignore o nome do escriptor": João Köpke, o tradutor
}

\author{
"Then, let no one suppose that I ignore the author's name": João \\ Köpke, the translator
}

https://doi.org/10.34112/2317-0972a2017V35n71p73-99

Norma Sandra de Almeida Ferreira ${ }^{1}$

Maria das Dores Soares Maziero ${ }^{2}$

RESUMO: Neste texto apresentamos uma faceta de João Köpke (1852-1926) anunciada mas pouco explorada pelos pesquisadores da história da educação e da literatura: a de tradutor. Trazemos parte de um conjunto de documentos, ainda não analisado, como objeto e fonte de pesquisa: 1) Três publicações em jornal $(1874,1882)$ sobre A morgadinha de Lyon (1874), tradução de Lady of lions, de Edward Bulwer-Lytton; 2) Tragédia de uma noiva (1875a), tradução de A bride's tragedy, de Dinah Maria Mulock Craik; As receitas do Dr. Marigold (1875b), tradução de Doctor Marigold's prescriptions, de Charles Dickens; 3) Manuscrito datilografado Conto de amor: Evangelina (s.d.), tradução de Evangeline, a tale of Acadie, de Henry Wordsworth Longfellow; 4) publicações em periódicos impressos: O corvo (1916, 1917), tradução do poema The Raven, de Edgar Allan Poe. Buscamos, em uma pesquisa de cunho exploratório, à luz dos estudos da História Cultural, aproximar ou distanciar aspectos ligados à prática de tradução de João Köpke a fim de investigar suas motivações e finalidades para tal prática.

PALAVRAS-ChAVE: João Köpke; tradutor; literatura do século XIX.

1. Universidade Estadual de Campinas, Campinas, SP, Brasil.

2. Faculdade de Paulínia, Paulínia, SP, Brasil. 
ABSTRACT: In this text we present a ability of João Köpke (1852-1926) that is little explored by researchers of history and literature: as a translator. We present part of a set of documents, yet to be analyzed as a whole, as the research object and source: 1) Three newspaper publications $(1874,1882)$ on A morgadinha de Lion (1874), translation of Lady of Lions, by Edward Bulwer-Lytton; 2) Tragédia de uma noiva (1875a), translation of $A$ bride's tragedy, by Dinah Maria Mulock Craik; As receitas do Dr. Marigold (1875b), translation of Doctor Marigold's prescriptions, by Charles Dickens; 3 ) Typed manuscript Conto de amor: Evangelina (s.d.), translation of Evangeline, a tale of Acadie, by Henry Wadsworth Longfellow; 4) publications in newpapers: $O$ corvo $(1916,1917)$, translation of The Raven, by Edgar Allan Poe. We tried, through this exploratory research, based on the studies of Cultural History, to approach aspects related to the translation practice of João Köpke in order to investigate his motivations and purposes for such practice.

KEY WORDS: João Köpke; translator; 19th century literature.

Estudos orientados pela perspectiva da História Cultural têm inventariado e mostrado um funcionamento e uma dinamicidade na cadeia produtiva, de circulação e de recepção dos livros, contemplando outros aspectos não privilegiados até então: autores desconhecidos e esquecidos; outras temáticas e novos gêneros discursivos; finalidades e práticas de leitura movimentadas de forma compartilhada em diferentes comunidades de leitores; ampliação dos espaços de leitura, de guarda, de circulação e de divulgação dos livros; diversidade de suportes - impressos, manuscritos, oralizados. Nuances são desenhadas em uma multiplicidade e compartilhamento de cada um desses aspectos, em cruzamentos e amplitude de fronteiras, além das dicotomias popular e erudito, centro e periferia, rural e urbano, local e estrangeiro, letrado e iletrado, consumo e produção, disciplina e liberdade. Evitando generalizações e abstrações, essa história é reinventada, entre práticas e representações (CHARTIER, 1990).

Pesquisas desenvolvidas nas três últimas décadas têm produzido uma reescrita da história dos livros, da leitura e dos leitores, por exemplo, do século XIX, em nosso país. O Rio de Janeiro, capital do Segundo Império e da Nova República (ABREU, 2013; WYLER, 1995, 2003), é visto como um centro de "dupla exposição cultural, a portuguesa e, por seu intermédio, a francesa” (WYLER, 1995, p. 70), fortalecida pelas missões artísticas, literárias, científicas e militares que ajudaram a fundar estabelecimentos de ensino, universidades e casas livreiras. É visto também como um espaço de circulação cultural que movimenta, que se expande e se firma em 
torno do impresso, "[...] em que as fronteiras nacionais não são um empecilho para o trânsito de livros, revistas, espetáculos [...]" (ABREU, 2016, p. 11).

São muitos espaços culturais - gabinetes de leitura, bibliotecas, institutos de arte, teatros e óperas, além das editoras e das livrarias que, atentas ao gosto do público leitor, põem em circulação romances e peças de teatro que resistem ao tempo, reeditados e retraduzidos, assim como também "[...] aqueles recém-saídos das prensas europeias, novidades em Paris e, ao mesmo tempo, no Rio de Janeiro" (MODENEZ, 2014, p. 230). São livreiros e editores que, atentos ao mercado editorial de livros escolares, solicitam traduções de obras da cultura universal destinadas às crianças (MAZIERO, 2015) e de livros de educadores como Fröebel, Pestalozzi, Menckdson, Locke e Comte (FERREIRA, 2015), entre outros, orientando políticas educacionais.

Autores nacionais - bacharéis, professores, funcionários públicos, médicos - participam de vários elos da cadeia produtiva e da circulação dos impressos, impulsionados pelo desejo de "semear" ideias para fortalecimento de uma nova nação (pós-Independência e pós-República), moderna e científica (positivista). Fazem parte de uma rede do poder político, composta por editores, livreiros, críticos, colegas de formação e de profissão, que ocupam cargos na instrução pública ou no governo. São escritores, mas também proprietários de jornais, organizadores de coleções, revisores, tipógrafos, palestrantes, jornalistas, tradutores de obras clássicas e recém-lançadas para um público leitor formado por adultos (incluindo mulheres) ou infantil (MAZIERO, 2015). Militam em diferentes instâncias (políticas, editoriais, literárias, escolares etc.), colocando obras em circulação, contribuindo para a formação de sistemas de referência cultural partilhados e espaços legitimados, incentivando determinadas práticas de leitura, contribuindo, no século XIX, para a formação e a ampliação do público leitor.

$\mathrm{Na}$ prática da socialização da leitura giram conversas, projetos, fundam-se associações (Academia Brasileira de Letras, 1897) e proliferam gabinetes e salas de leitura, revistas especializadas, periódicos diversificados para mulheres, crianças, operários. Movimenta-se o espaço onde se pode falar de livros e em nome deles quer pelo interesse financeiro, quer pela demanda de consumo, pela crença na força de sua existência ou por "exibição de talentos reprimidos" (WYLER, 1995, p. 100) ou, ainda, pelo prestígio e status agregados aos escritores do século XIX. Como diria Bourdieu (1996, p. 238), "é possível que se leia quando existe um mercado no qual possam ser colocados os discursos concernentes às leituras”. 


\section{A ATIVIDAde DA TRADUÇão}

Para Wyler, o Oitocentos é o século da tradução escrita, que é a "protagonista da cena cultural do Segundo Império Brasileiro" (WYLER, 2003, p. 42). Impulsionada indiretamente pela vinda da Corte Portuguesa para o Rio de Janeiro e pela criação da Imprensa Régia, a tradução escrita (WYLER, 1995) é estimulada pela prática cultural de apreciação dos dramas, das peças de teatro, das óperas e dos romances-folhetim - impressos, encenados, ouvidos.

Segundo Vasconcelos (2016, p. 137), um estudo dos catálogos à disposição dos leitores, em meados do século XIX, fornece "[...] um retrato em miniatura do que era o mercado novelístico de então - romances franceses, ingleses e portugueses, autores consagrados e anônimos [...]", com amplo e ágil trânsito internacional, marcado especialmente pela circulação de livros traduzidos e impulsionado, entre outros motivos, pela ação de livreiros, comerciantes de livros e editores, que tinham "[...] a responsabilidade de imprimir, transportar, transladar, transpor de uma língua para outra, de uma cultura para outra, textos de um determinado sistema ou tradição" (VASCONCELOS, 2016, p. 138).

A tradução, que representava praticamente a metade das obras oferecidas nos catálogos, é assumida por profissionais liberais, "homens com talento para línguas, com diploma de ciência na mão ou de humanidades e também de 'colunáveis do Império”" (WYLER, 1995, p. 110), que, traduzindo uma única obra ou várias, na maioria das vezes permaneciam exercendo suas profissões de origem, sujeitando-se a remunerações pouco vantajosas e até mesmo, em alguns casos, sem ver seus nomes estampados junto ao dos autores traduzidos.

Em um exercício de caráter acadêmico ou prazeroso, como "[...] ocupação temporária das elites intelectualizadas” (WYLER, 1995, p. 62), as traduções ganhavam sentidos distintos e dispersos em muitas configurações: imitação, cópia, adaptação, translação, paráfrase, "criação" - formas coexistentes, por exemplo, no contexto brasileiro do século XIX. Uma significativa e diversa produção situada entre fazer uma tradução literal, o mais próxima possível do original, e uma outra, com mais autonomia em relação ao texto-fonte.

Duas questões estavam postas, nesse período: a importância da adaptação para dar "cor local" às obras estrangeiras e, em outra direção, o cuidado com a qualidade "literária" da translação, de modo a conservar a beleza e a arte do original expressas pelo escritor. De qualquer modo, um trabalho que põe em contato dois universos 
de referência, duas línguas, duas culturas, que descontextualiza uma obra e a recontextualiza, "operando o que se pode chamar de uma verdadeira 'tradução cultural" (VASCONCELOS, 2016, p. 146). De certo modo, também, uma atividade que, feita às pressas e sem rigor, aviltava o trabalho dos tradutores, que recebiam qualquer quantia dos empresários teatrais e dos proprietários de jornais, preocupados em atender à crescente demanda de repertórios variados e novidades estrangeiras para um público que se estendia pelos saraus, folhetins e tablados (WYLER, 2003).

\section{JOÃO KÖPKE: O TRADUTOR}

Lia Wyler, em Línguas, poetas e bacharéis - uma crônica da tradução no Brasil (2003), aborda a polêmica questão da invisibilidade do tradutor, profissão liberal reconhecida desde o século XIX, mas apenas no segmento dos tradutores públicos ou juramentados que prestam concurso nas Juntas Comerciais Estaduais. Destaca ainda o fato de que a história da tradução em nosso país tem sido pouco explorada na perspectiva dos estudos historiográficos.

João Köpke (1852, Petrópolis-RJ; 1926, Rio de Janeiro-RJ), ainda que não tenha sido tradutor profissional, pode ser ilustrativo das atividades da categoria, uma vez que, como intelectual do século XIX e início do XX, exercia tal atividade, entre tantas outras, no cenário cultural de nosso país. No entanto, os trabalhos que estudaram sua formação pessoal e acadêmica, assim como sua atuação profissional (FERREIRA, 2017; MORTATTI, 200o; PANIZZOLO, 2006; SANTOS, 2013), não se aprofundaram nos aspectos relativos à atuação de Köpke como tradutor, perspectiva ainda pouco explorada pelos pesquisadores da história da educação e da literatura, embora anunciada em algumas dessas pesquisas. O domínio de línguas estrangeiras atribuído a João Kopke, entre outros aspectos de sua trajetória, é referência nessas pesquisas como indicativo de sua formação humanística e universal, de sua atuação como professor de francês, inglês, italiano, como um homem que em um período de sua vida pôde viver desse tipo de publicação em periódicos, como um mestre que lê educadores estrangeiros, na língua original (HILSDORF, 1986; MENEZES, 1980; entre outros).

Neste texto, buscamos, em uma pesquisa de cunho exploratório, à luz dos estudos da História Cultural (CHARTIER, 1990), aproximar ou distanciar aspectos ligados especialmente à prática de tradução de João Köpke. Indagamos a respeito dos seguintes pontos: que sentidos podem ser inferidos a partir do conhecimento 
da data de publicação, do autor, do espaço de circulação e de recepção das obras que inspiraram as traduções feitas por Köpke? Quais parecem ter sido as motivações e as finalidades de João Köpke para essas traduções?

Trazemos parte de um conjunto de documentos reunido por Santos (2013) e Ferreira (2017), ainda não analisado como objeto e fonte de pesquisa. São três tipos de documentos referentes às seguintes traduções de João Köpke: 1. Três publicações em jornal $(1874,1882)$ sobre A morgadinha de Lyon (1874), de Edward BulwerLytton; 2. Tragédia de uma noiva (1875a), de Dinah Maria Mulock Craik; As receitas do Dr. Marigold (1875b), de Charles Dickens; 3 ) Manuscrito datilografado Conto de amor: Evangelina (s.d.), de Henry Wadsworth Longfellow; 4. publicações em periódicos impressos: O corvo $(1916,1917)$, de Edgar Allan Poe. Tomamos como desafio apresentar essa produção de Köpke no interior das obras que circularam e tiveram recepção no cenário cultural do final do século XIX e início do XX, em nosso país. Destacamos um modo de Köpke de lidar com a linguagem escrita - na tradução que se aproxima de suas outras práticas de escrita abordadas por Ferreira (2017).

$\mathrm{Na}$ leitura desse material, organizamos essas traduções, situando-as quanto ao período de atuação (1874-1917) de João Köpke, em três momentos distintos. O primeiro momento reúne Tragédia de uma noiva ( $1^{\mathrm{a}}$ e $2^{\mathrm{a}}$ partes), de Dinah Maria Mulock Craik; A morgadinha de Lyon, de Edward Bulwer-Lytton e Receitas do Dr. Marigold, de Charles Dickens. O segundo é caracterizado pela tradução de Evangelina, de Henry Longfellow. Por último, trazemos O corvo, de Edgar Allan Poe.

\section{UMA PRIMEIRA ORGANIZAÇÃO NO TEMPO}

Nota publicada no jornal Diário de São Paulo, em 1874, anuncia a atividade de João Köpke como tradutor, informando o lançamento da primeira edição da obra A morgadinha de Lyon:

Acha-se no prelo e brevemente verá a luz da publicidade, uma esmerada tradução do drama de Bulwer - A morgada de Lyão - feita pelo inteligente acadêmico, o sr. João Kopke. $\mathrm{O}$ drama de Bulwer é um interessante romance do orgulho da nobreza antiga, subjugado por uma paixão invencível no momento em que a aç̧ão desta devia revoltal-o; atravez desta urdidura apresentão-se episodios curiosos de costumes, um dos caracteristicos do genio do autor inglez. (Diário de São Paulo, 20 ago. 1874, p. 3). 
Três meses após a publicação da nota do Diário de São Paulo, o redator da Gazeta de Campinas informa aos leitores do periódico ter recebido um exemplar da peça A morgadinha de Lyon, que havia, portanto, sido impressa:

Fomos obsequiados com um exemplar da Morgadinha de Lyon do afamado escriptor E.L. Lyton, peça vertida em portuguez pelo talentoso academico Sr. João Köpke. A traducção nos parece esmerada e digna do original, revellando o seu author pronunciados e estimaveis dotes para commentimentos dessa natureza, bem como para de outros gêneros de trabalhos litterarios a que lhe abrem do bem direito os recursos do espirito e do estudo. (o8 nov. 1874, s.p.)

E, em outra nota publicada pelo Jornal A Provincia de São Paulo, ficamos sabendo que, além de haver sido publicada na forma de livro impresso, a obra também fora encenada no Theatro S. José, na cidade de São Paulo, no dia 10 de agosto de 1882:

[...] receita concedida em benefício do ator J. Augusto com a 1.a. apresentação do excelente drama em 5 atos e 6 quadros, original inglês, primorosa tradução do Sr. dr. João Kopke: Morgadinha de Lyon. [...]. (A Provincia de São Paulo, 10 ago. 1882, p. 3).

Assim, o que é possível inferir é que houve uma publicação na forma de livro impresso de A morgadinha de Lyon e que, segundo essas três matérias de jornal, seria uma tradução "primorosa", "esmerada e digna do original", de autoria de um tradutor talentoso, estudioso e inteligente. Publicada em forma de livro e posteriormente encenada, essa obra indicia alguns pontos: o interesse do público por dois suportes distintos de uma mesma história (impresso e encenado); a existência de práticas de leitura do impresso e também, em alguns casos, da encenação teatral de obras já publicadas; um possível alargamento do público para além daquele conhecedor da literatura impressa e em língua estrangeira.

Apesar da falta de um exemplar da tradução feita por Köpke³, o que permitiria cotejar o texto traduzido para o português com a versão em inglês, uma questão que se coloca é o título dado pelo tradutor ao drama escrito por Bulwer-Lytton, originalmente The lady of Lyons, or Love and pride (A dama de Lyons, ou Amor e

3. Infelizmente não localizamos um exemplar traduzido da obra The lady of Lyons, or Love and pride, de Edward Bulwer-Lytton. Uma edição em inglês está disponível no Projeto Gutenberg. Verifique nas referências. 
orgulho, em tradução direta), mas que, na versão do acadêmico brasileiro, ganhou o termo "morgadinha", distante do significado de "lady".

The lady of Lyons é um melodrama que gira em torno da senhora de Lyon, Pauline Deschapelles, disputada por dois pretendentes a seu marido: o Marquês Beauséant, que prometera quitar a dívida do pai da moça, ameaçado de falência, e Claude Melnotte, filho do jardineiro de Pauline que, apaixonado pela moça, se disfarça de príncipe estrangeiro para tornar-se seu marido. Pauline se casa com Claude, mas, ao conhecer a sogra, descobre que havia sido enganada por Melnotte, conseguindo a anulação do casamento. Melnotte, desgostoso e cheio de remorsos por enganar a amada, alista-se no exército e torna-se um herói de guerra. Nesse meio tempo, Pauline descobre que é apaixonada por ele, e os dois finalmente podem ser felizes.

Como vemos, o drama de Bulwer-Lytton enquadra-se no ideário romântico, que tantas vezes tematizou o triângulo amoroso - a jovem inocente e apaixonada, além de boa filha; o jovem pobre que enfrenta preconceitos da sociedade e torna-se herói; o vilão, um nobre que tenta impedir o amor de um casal. Enquadra-se, ainda, no gênero -romance vitoriano que tratava "[...] o modo de vida urbano, industrial e burguês de uma sociedade inglesa, cada vez mais estratificada e complexa, multifacetada pelas ansiedade e conflitos" (RAMICELLI, 2016, p. 104).

Se a obra de Bulwer-Lytton (1838), produzida especialmente para ser encenada no Teatro Covent Garden, em Londres, recebeu críticas favoráveis e foi bem aceita pelo público (LYTTON, 2008, além de haver sido adaptada para o formato de óperas e operetas ao longo do século XIX, a tradução de Köpke não passou da primeira edição, e não localizamos notícia de nenhuma outra tradução para o português desta obra do escritor inglês.

Quanto à Tragédia de uma noiva, de Dinah Maria Mulock Craik (1826-1887), publicada em duas partes e conclusão no jornal A Provincia de São Paulo, nos dias 01, o8 e 13 de abril de 1875, é tradução de um gênero - romance folhetim - que ganhara o gosto do público há algumas décadas (CANDIDO, 1975; HALLEWELL,

4. Segundo o dicionário Michaelis, o termo "morgado" se refere "ao filho primogênito de família em que havia bens vinculados". O termo "morgadinha" esteve presente no título de outras obras de autores românticos portugueses que circularam no Brasil durante o século XIX, e que parece terem alcançado bastante sucesso, como A morgadinha dos canaviais (1868), de Júlio Dinis, e A morgadinha de Valflor (1869), de Manuel Pinheiro Chagas, sendo que o enredo desta última obra se aproxima especialmente do enredo de A morgadinha de Lyon, o que talvez tenha levado Köpke a definir o título de sua tradução para a obra de Bulwer-Lytton. 
2005).5 De fato, a história é apresentada com destaque na seção FOLHETIM, na primeira página do jornal, como ocorria na maioria das publicações desse gênero. Ocupando horizontalmente a parte de baixo da folha (como uma longa nota de rodapé), lemos os créditos de autoria e o título: "Tragédia de uma noiva, por Wilkie Collins, Trad. direto do inglez por João Köpke. $1^{\text {a }}$ parte” (Jornal Provincia de São Paulo, $1^{\circ} / 04 / 1875 a$, p. 1).

Em um primeiro momento, a autoria do texto traduzido foi atribuída erroneamente ao escritor inglês Wilkie Collins (1824-1889), o que provocou a publicação de uma nota no Jornal Diário de São Paulo, em 02 de abril de 1875, ironizando o equívoco:

\section{Errata}

O romance que a Provincia de São Paulo começou a publicar em folhetins não é de Wilkie Collins, mas de John Halifax.

\section{Quod Caesaris Caesari. 6}

$1^{\circ}$ de Abril. (Jornal Diário de São Paulo, 02 abr. 1875, p. 2)

Em resposta ao conteúdo desta "Errata", o próprio Köpke se pronunciou através de A Provincia de São Paulo, de 03 de abril de 1875 (b), assumindo o equívoco e explicando os motivos que o levaram a cometê-lo:

Rectificação. - O distincto academico sr. João Köpke, a quem devemos a tradução do folhetim que estamos dando na folha, escreve-nos o seguinte, rectificando um engano na indicação do nome do autor do romance traduzido: "Sr. Redactor - Começando hontem no seu jornal a publicação da minha tradução Tragedia de uma noiva, com espanto e desgosto meu, vi que sahiu como original de Wilkie Collins, quando não o é, porém sim de John Halifax. Tal equivoco é devido a ter eu estado lendo, na ocasião em que fui levar a tradução ao sr. Lisboa, um trecho da Pedra da Lua ao sr. Americo de Campos. E como este ultimo romance é de Wilkie Collins, quando o dr. Americo pediu-me o nome do autor da Tragedia, por equívoco dei o deste ultimo escriptor.

5. Em meados do século XIX, os jornais publicavam folhetins, de forma seriada, como estratégia para prender o leitor: "A publicação na forma de folhetim encorajava os complicados enredos melodramáticos, sendo cada parte planejada para terminar de forma a deixar o leitor aguardando ansiosamente a continuação [...]. O Brasil, como sempre o fizera, imitou a França, embora não antes de 1839 [...]. A grande maioria dos romansfeuilletons brasileiros era constituída por traduções" (HALLEWELL, 2005, p. 210-211), quantitativamente abundantes “[...] nos jornais, não apenas do Rio, mas de todo o país”. (CANDIDO, 1975, p. 120).

6. A César o que é de César. 
"Que ninguem supporá que eu ignore o nome do escriptor": João Köpke, o tradutor

Qualquer pessoa poderia cahir no mesmo por distracção, como a minha e ninguem supporá que eu ignore o nome do escriptor, que verti, porque, além de vir elle em qualquer catalogo de romancistas inglezes, como autor das Historias Domesticas, de onde extrahi a tradução, que ora se publica, acha-se tambem estampado no frontespicio da obra. [...]

Rogo-lhe pois, sr. redactor, a publicação destas linhas, afim de que fique sanado o meu equivoco, e tapada a boca a qualquer critica de esquina, de cuja má lingua ninguem está livre. Haja vista o artiguete do Diario, sob o titulo "Errata”, que julgo partir de um amigo que me censura, porque eu mesmo lhe apontei o meu equivoco".

S. Paulo, 2 de abril de 1985.

João Köpke

O inusitado nesse episódio, porém, é que o autor da "Errata" publicada pelo Diario de São Paulo acertou ao dizer que a obra traduzida por Köpke não havia sido escrita por Wilkie Collins, mas errou ao atribuir a autoria a John Halifax, que na realidade é apenas a personagem principal do livro John Halifax, Gentleman, publicado em 1857, que alcançou grande sucesso entre os leitores. A autora é Dinah Maria Mulock Craik (1826-1887), novelista e poeta inglesa.

Tragédia de uma noiva ( $A$ bride's tragedy), como Köpke afirma em sua carta de esclarecimento publicada n'A Provincia de São Paulo, é um dos 14 contos que fazem parte do livro Histórias domésticas (Domestic stories), publicado em 18597.

$\mathrm{O}$ que teria levado João Köpke a se equivocar quanto ao nome do autor da obra que estava traduzindo, se, conforme ele próprio afirma, tinha em mãos o exemplar de Histórias domésticas, disponível “[...] em qualquer catalogo de romancistas inglezes $[\ldots]$ ”?

Consultando um exemplar da obra disponibilizado digitalmente, constata-se que não é mencionado em nenhuma parte deste o nome da autora (nem mesmo na capa do livro), havendo, ao invés disso, apenas a expressão, colocada logo após o título: "By the author of 'JOHN HALIFAX, GENTLEMAN'”.

7. Foi consultada uma cópia digital da obra, disponibilizada pela Universidade de Indiana, no seguinte endereço: <https://babel.hathitrust.org/cgi/pt?id=inu.39000003451189; view=1up;seq=346>. Acesso em: 03 mar. 2017.

8. Tivemos acesso a outra obra de Dinah M. M. Craik, The woman's kingdom, publicação antiga, em dois volumes, sem indicação de data, da "Leipzig: Bernhard Tauchnitz", na qual também não há menção ao nome do autor em nenhuma parte do livro, seja na capa ou na página de rosto. Há apenas, no verso da página de apresentação, uma lista anunciando outras obras da Tauchnitz editions "By the same Author”. Nessa lista, além de outras obras de Dinah M. M. Craik, aparece o título Domestic stories e a indicação de que se trata 
Desse modo, é possível pensar que a edição de Domestic stories a que Köpke teve acesso pudesse seguir o mesmo padrão, daí o equívoco cometido tanto por ele quanto pelo autor da Errata publicada no Diario de São Paulo. Tal gesto - ausência de indicação da autoria - pode ser um recurso editorial do gênero, que se escondia sob pseudônimos masculinos, ou, ainda, exibia apenas as iniciais do primeiro nome das escritoras, na época.

Na tradução de Köpke para o conto de Dinah M. Mulock Craik publicada por $A$ Provincia de São Paulo, em duas partes e uma conclusão, o leitor conhece a história de Alice W., que, apesar da resistência de seu pai e de outros familiares, consegue casar-se com sua grande paixão, Arthur Silvester. Após a cerimônia de casamento, a narradora - uma prima mais velha que ajudara na criação de Alice após a morte da mãe desta - vai até o jardim para chamar o casal, quando, subitamente, ouve um grito e encontra a noiva

[...] de olhos dilatados de medo, sua face gelada, numa expressão do mais feroz terror. Do seu braço corria sangue, gota a gota, que caía em seu vestido branco. Debruçado sobre ela, o noivo tinha na mão um punhal [...] ele deixou tombar a arma e precipitou-se, com um uivo semelhante ao de um animal feroz, numa carreira vertiginosa atravez dos campos. Arthur Silvester enlouquecera no dia do seu noivado. (E continua). (KÖPKE, 1875a, p. 1).

O enredo se desenrola com o sofrimento amoroso vivido pelos personagens. Arthur Sylvester, por exemplo, literalmente enlouquece de arrependimento por dilacerar dois corações: o da esposa Izabel, a quem abandonara para se casar com Alice W., interessado apenas em sua riqueza, e o da própria Alice, vítima da violência de um marido do qual não sabe o paradeiro. Novamente uma triste história de amor, que se desenrola em meio a crises de consciência, dramas existenciais, traições e jogo de poder, que parecem marcar os folhetins, tão ao gosto do público daquela época.

Ainda uma terceira tradução feita para A Provincia de São Paulo nesse mesmo ano $(1875 \mathrm{~b})$ também pode ser citada como exemplo dessa fase em que João Köpke se dedicou a verter para o português textos de autores românticos ingleses. Trata-se de As receitas do doutor Marigold, tradução do conto Doctor Marigold's prescriptions, escrito pelo consagrado escritor Charles Dickens (1812-1870).

de volume único. Na capa dessa obra, logo após o título, também aparece a informação: "BY THE AUTHOR OF 'JOHN HALIFAX, GENTLEMAN'”. 
A primeira versão de Doctor Marigold's prescriptions saiu em 1865, no número extra de natal do periódico All the year round, editado e dirigido por Charles Dickens ${ }^{9} \mathrm{Em}$ 1874, recebeu nova reimpressão na obra Christmas stories, desta feita apenas como Doctor Marigold, porém numa versão encurtada. A história relata as aventuras de Doutor Marigold, um vendedor ambulante que recebeu o nome de "Doutor" em homenagem ao bondoso médico que o trouxera ao mundo. Após a trágica morte de sua filha Sophy e do suicídio da esposa, Doutor Marigold adota uma pobre menina órfã, surda e muda, a quem dá o mesmo nome de sua falecida filha. Ele consegue ensiná-la a ler e a se comunicar, mas, ao completar 16 anos, a garota é levada por ele para frequentar uma escola para surdos-mudos, em Londres, onde permanece por dois anos, período em que Doutor Marigold decide escrever suas "prescrições" para ela, na forma de algumas histórias coletadas e copiadas por ele numa espécie de livro.

O conto de Dickens, na versão publicada em 1865, está dividido em oito partes, como se fossem as indicações de um médico sobre o modo como um medicamento deve ser tomado. A tradução de Köpke para Doctor Marigold's prescriptions foi publicada pela Provincia de São Paulo com o título de As receitas do doutor Marigold, no período compreendido entre 21 de abril e 29 de maio de 1875 , quase sempre na página 2 do jornal, dentro da coluna de "Variedades", mas não na íntegra, apenas as prescrições I e II ("Para tomar imediatamente" e "Não tome ao deitar"), o que corresponde a aproximadamente $25 \%$ do texto original de Charles Dickens.

Essa tradução se ateve à estrutura dada à obra por Dickens; a primeira prescrição - que vai da explicação do nome da personagem, passando pelos fatos trágicos de sua vida, a adoção de Sophy e a ida desta para a escola de surdos-mudos em Londres, até seu feliz regresso à casa, após dois anos; e a prescrição "Não tome ao deitar", que é a primeira das seis histórias que Doutor Marigold havia reunido no livro que preparara para a filha durante o período em que esta esteve afastada dele.

$\mathrm{O}$ que teriam pensado os leitores sobre a interrupção das publicações? Teriam os mais atentos estranhado o fato de, apesar de o título continuar o mesmo, na parte II não aparecerem mais as personagens Doutor Marigold e Sophy? Difícil responder, mas esses leitores deixaram de ler o final feliz de Dickens (prescrição número VIII: "To be taken for life"), quando Sophy, o marido e a filha voltam para

9. Versão digital da obra feita pela University of California Libraries. Disponível em: <https://archive.org/ stream/doctormarigoldspoodickrich\#page/n3/mode/2up >. Acesso em: 10 jul. 2017. 
a Inglaterra e reencontram Doutor Marigold, que fica radiante com o reencontro e com o fato de saber que sua neta podia falar e ouvir, ao contrário de seus pais.

Porém, o que talvez possa explicar a não continuidade de publicação das traduções de Köpke em A Provincia de São Paulo sejam as mudanças ocorridas em sua vida pessoal e profissional: no final de 1875 ele foi nomeado promotor público em Faxina (SP), mudando-se da cidade de São Paulo, conforme relata em belíssima carta escrita a José Maria Lisboa, em 31/10/1875c.

Essas três traduções publicadas em datas próximas entre si foram realizadas quando Köpke cursava o quarto ano do Largo São Francisco (1874) e no ano em que ele se formou bacharel em Direito (1875), época em que já era reconhecido como excelente professor da escola anexa à Faculdade de Direito, além de ter publicado sua primeira cartilha, intitulada Méthodo Rapido para aprender a ler (1874, pela Laemmert). Já casado (1872), preparava-se para tornar-se pai pela primeira vez. É um período em que ele precisava trabalhar muito para sustentar sua família e prosseguir nos estudos por conta própria. Assim, além das aulas particulares de inglês, conforme atestam vários anúncios publicados n’A Provincia de S. Paulo (SANTOS, 2013), assumiu também a função de colaborador (como tradutor) de A Provincia de S. Paulo (MENEZES, 1980).

Nessa época, suas traduções são, portanto, produto de um trabalho profissional bastante em voga na época e que em alguns casos oferecia bom retorno financeiro. Segundo Hallewell (2005, p. 211), "por volta de 1870, mesmo um escritor desconhecido poderia receber mais ou menos $70 \$ 000$ por mês pela tradução [...]”. Köpke explora, desse modo, o seu domínio da língua inglesa, nas atividades de tradução e de ensino, o que parece acompanhá-lo por grande parte da vida.

\section{UMA SEGUNDA ORGANIZAÇÃO NO TEMPO: EVANGELINE, UM CONTO DE AMOR}

Evangeline, um conto de amor, de Herry Longfellow, publicado inicialmente em 1847, é uma escolha de Köpke que se sustenta no gênero drama, do Romantismo, do qual ele já traduzira obras anteriormente.

Por outro lado, a escolha de Evangeline pode ter se dado também pelo interesse já reconhecido de Köpke pelas obras clássicas gregas e latinas que atravessaram séculos, cantadas pelos poetas, encantando os homens pela musicalidade das expressões, como sugestões e estímulos à imitação do belo e do bem, como educação moral dos povos (FERREIRA, 2017). 
Evangeline, de Henry W. Longfellow ${ }^{10}$, é uma história que correu o mundo. Publicada em 1847, rendeu sucesso imediato a seu autor, sucedendo-se versões em língua estrangeira, centenas de edições por diferentes países, filmagens, músicas etc.

No Canadá, essa obra é considerada o mito fundador da Acádia ${ }^{11}$. Para Campos e Ramos (2009), "os povos acadianos têm orgulho de sua história, a qual foi mitificada pelo célebre poema do norte-americano Henry W. Longfellow: Evangeline: a tale of Acadie, e sua protagonista continua povoando o imaginário coletivo, "sendo ainda hoje o símbolo da singularidade e da coragem do povo acadiano" (CAMPOS; RAMOS, 2009, p. 161).

O poema enfatiza a história de amor de Evangeline Bellefontaine, a heroína que no dia de seu casamento é separada do noivo, Gabriel Lajeunesse, por causa da deportação imposta a seu povo pelos ingleses, em 05/09/1755. Grande parte do poema mostra a protagonista percorrendo paisagens da América em busca de seu amor, durante muitos anos. Indo atrás de pistas dadas por outros personagens, ela, algumas vezes, chega ao lugar logo após a partida do amado, ou então não é capaz de saber que ele estava bem próximo de si. Só consegue reencontrá-lo, já mais velha, quando trabalhava como enfermeira em um hospital em Filadélfia. Seu amor, Gabriel, enfermo nesse hospital, morre, então, em seus braços.

Evangeline, de Henry Longfellow, parece ter tido boa aceitação pelo público leitor brasileiro, no século XIX, considerando-se o número de traduções que circularam em nosso país, possíveis de serem adquiridas atualmente em sebos virtuais.

Nesse período, pelo menos duas traduções de Evangelina foram editadas: a de Franklin Dória (1836-1906), publicada pela E. e H. Laemmert, em 1874, e a de Americo Lobo (1841-1903) ${ }^{12}$, em 1884, pela Tipografia G. Leuzinger e filhos, no Rio de Janeiro. Ambos os autores são bacharéis, contemporâneos de João Köpke, tornaram-se homens públicos e estiveram próximos de D. Pedro II, posteriormente assumindo cargos

10. O exemplar no qual apoiamos nossa análise é de 1921, impresso no Canadá e está disponível virtualmente na biblioteca de Toronto.

11. "Antiga região oriental do Canadá francês. Até 1713, foi disputada por franceses e ingleses; nesse ano, a região passou definitivamente para a posse inglesa, pelo Tratado de Utrecht, e tornou-se desde então a Nova Escócia. Em 1755, o governo inglês expulsou toda a população francesa - 10 mil pessoas - para a Nova Inglaterra”. (Grande Enciclopédia Larousse Cultural, 1987, vol. 1, p. 34).

12. Em uma busca em sebos virtuais por traduções nacionais, localizamos a tradução de Franklin Dória (Ed. Laemmert, 1874), disponível em <https://ihgb.org.br/pesquisa/biblioteca/item/19148-evangelina-h-wlongfellow-traduzida-do-original-inglez-por-franklin-doria.html >, e adquirimos um exemplar de 1884, typ. G. Leuzinger e Filhos, traduzido por Americo Lobo. 
na Nova República e produzindo obras que, assim como Evangeline, traziam, além dos temas românticos, tão ao gosto do público brasileiro daquele período, o tema da busca da identidade nacional de um povo (luta por território geográfico e político), assim como sua cultura, religião e sobrevivência na história de um país.

É provável que Köpke tenha tomado conhecimento dessas traduções nacionais, pois, assim como seus colegas, também circulou pelos salões de D. Pedro II, fez parte da rede dos republicanos e, em 1886, já tinha voltado a morar na cidade do Rio de Janeiro. Talvez a existência dessas traduções (DÓRIA, 1874; LOBO, 1884) que circulavam no Rio de Janeiro tenha desestimulado Köpke a concluir sua versão, embora saibamos que apenas este fato não o impediria de ir em frente, tal como o fez com $O$ corvo, já traduzido anteriormente por Machado de Assis e por outros contemporâneos dele.

A tradução de Evangeline ${ }^{13}$, de Henry Longfellow, feita por Köpke, é um manuscrito datilografado ${ }^{14}$, composto de 51 folhas soltas e amareladas, numeradas até a de número 37 (a partir de então, sem numeração). ${ }^{15}$

Sem capa, o manuscrito traz, na página inicial, as seguintes informações: "Conto de amor" [espaço] "como o teria narrado em portuguez." [espaço] "Henrique Wadsworth Longfelllow," "poeta americano", "seu autor" [espaço]. "Collaboração de João Köpke e seu filho Winckelmann Köpke.”

O esmero na apresentação visual dessas informações - jogo de cores nas letras, título em diagonal, espaçamento diferente; configuração de uma estrofe de cinco versos, com rimas etc. - sugere um escritor laborioso e dedicado, qualidades também percebidas em outros manuscritos de João Köpke (FERREIRA, 2017).

A narração em português de Evangelina é o trabalho precioso de um datilógrafo que domina essa técnica. ${ }^{16}$ As poucas correções do texto datilografado, a lápis, apon-

13. A família Köpke cedeu ao nosso grupo de pesquisa ALLE/FE/Unicamp, uma Pasta que guarda, além dos Versos para os pequeninos, de João Köpke (FERREIRA, 2017), os textos: Conto de amor - Evangelina (Longfellow); O pássaro dourado (sem identificação de autoria) e O casamento de Panurgo (Rabelais). Os dois últimos não trazem qualquer referência à autoria da tradução ou adaptação.

14. Para Vasconcellos (2010), o termo "manuscrito" pode ser entendido como um conjunto de documentos: autógrafos, datilografados, digitados, éditos ou inéditos, ampliando, assim, as definições anteriores para além da escrita de próprio punho (cursiva ou de fôrma).

15. Em uma leitura do material, constatamos que se trata de duas versões (traduções) datilografadas da mesma parte do poema, sendo a segunda iniciada imediatamente após o final da primeira (página 37) e sem qualquer marca que indicasse a distinção entre elas.

16. Não podemos precisar qual foi exatamente a "colaboração" de Winckelmann: se de datilógrafo, se opinando na escolha da melhor palavra na tradução. De qualquer forma, é possível afirmar que João Köpke não só dominava a língua estrangeira e publicou Lições de Inglês e Cursos de Francês (MENESES, 1980), como também enviou cartas datilografadas a diferentes destinatários (FERREIRA, 2017). 
tam para letras incorretamente registradas ou substituição de palavras por sinônimos, sugerindo a ação de um autor-revisor que faz a leitura inicial e geral de uma versão que não tem pretensão de apresentar a leitores ou a um editor. Talvez houvesse ainda outro(s) texto(s), em letra cursiva, ou a versão em inglês, para dar apoio a esse trabalho. Quanto à data de elaboração dessa tradução de Evangelina, é difícil precisar. Talvez ela esteja situada entre os primeiros trabalhos de João Köpke, já comentados (1874/1875), e o último, O corvo, de Edgar Allan Poe $(1916,1917)$. O seu período de produção só pode ser inferido perseguindo a indicação, na primeira página, do nome de Winckelmann Köpke como colaborador. Para atuar nessa função, pressupõe-se que ele já fosse um jovem rapaz, considerando que nasceu em 25/o1/1886.

Se esta hipótese for possível, a tradução de Evangeline estaria situada no período em que João Köpke provavelmente já havia fechado o Instituto Henrique Köpke (1897) e Winckelmann já estudava em outros colégios que não o do seu pai, participando de homenagens ao diretor Leôncio Correa e ao Barão de Macaúbas, conforme matérias publicadas no Correio da Manhã de 29/05/1902 e de 04/06/1904.

É um período no qual João Köpke precisou lidar com mais dificuldades financeiras para sustentar seu Instituto (FERREIRA, 2015, 2017), tendo se dedicado às aulas particulares e à revisão das edições de seus livros de leituras morais e instrutivas, editados de 1884 até meados do século XX (SANTOS, 2013), até ser nomeado para ocupar o cargo de tabelião oficial de registro geral e de hipotecas no Rio de Janeiro.

Cotejando a versão de Evangelina feita por João Köpke (s.d.) com uma de Longfellow publicada em 1921, vemos que ambas apresentam a mesma disposição das partes e um conteúdo muito próximo. O poema de Longfellow é dividido em três partes: "Prelúdio"; "Primeira Parte"; e "Segunda Parte", sendo cada uma delas composta de cinco cantos (subdivisões). Igualmente, o manuscrito de João Köpke traz a "Introdução" e as subdivisões que compõem a "Primeira Parte", porém sem avançar para a "Segunda Parte".

A constatação do esmero na produção da página de rosto de duas versões de uma mesma parte da obra e das intervenções na busca de outros sinônimos para uma mesma expressão indiciam um autor que investe tempo, trabalho e dedicação na reescrita de seus textos. No entanto, ficam as perguntas: Seria Evangelina um exercício de tradução, ainda em fase bastante preliminar? Um trabalho compartilhado 
por pai e filho, em uma relação de ensino-aprendizagem da língua inglesa, ou teriam se perdido as versões mais bem acabadas desta tradução?

UMA TERCEIRA ORgANIZAÇÃO: $O$ CORVO

Como sabemos, o poema $O$ corvo, de Edgar Allan Poe, tematiza, como os demais dramas analisados por nós, o sofrimento e a dor sentidos pelo narrador lírico diante da inexorabilidade da morte: "[...] que minha alma chora/ Não sai mais,/ nunca, nunca mais!” (KÖPKE, 1917, p. 86). Os versos falam de alguém apaixonado, triste e solitário em razão da morte de sua amada Leonora - que recebe a visita de um corvo, "ave ou demônio", também solitário, magro e rude, que, insistentemente, repete o verso "nunca mais" para o estupefato narrador lírico.

O poema The raven, de Edgar Allan Poe, parece ter tido uma ampla circulação no Brasil do final do século XIX e início do XX. O autor é lembrado por literatos que deram depoimentos a João do Rio (1994), como, por exemplo, Nestor Vitor (1868-1932) e Garcia Redondo (1854-1916) que, em tempos de "república", como estudante de Direito, lia, entre outros, Edgar Poe, que "encantou-me e assombrou-me" (RIO, 1994, p. 168). Poe é lembrado por João Köpke por outras traduções da obra, algumas delas apresentadas no Teatro Municipal do Rio de Janeiro, como, por exemplo, a de Machado de Assis, "em tom de conversa" (KÖPKE, 1917, p. 368); a encenada no palco, demonstrando que o ator no momento da apresentação da peça "não comprehendeu nem o que o poeta nitidamente exprimia, nem o que a intellingencia e o coração tem forçosamente de ler nas entrelinhas" (KÖPKE, 1917, p. 368); e a de Bilac e Oliveira, "[...] magistral, porém bem diversa era a que impressionantemente lhe dava Edgar Poe" (KÖPKE, 1917, p. 368).

Apresentada de forma oralizada, a tradução de $O$ corvo feita por João Köpke é, primeiramente, apreciada pela prática da palavra ledora diante de um público interessado na programação de leitura, em sarau promovido pela Sociedade de Cultura Artística (SP), conforme destaca a matéria de 14/o5/1916, de O Estado de S. Paulo.

Essa matéria, publicada na parte final da página 2, com a chamada "ARTES E ARTISTAS - Sociedade de Cultura, Artes e Letras - A leitura de 'O Corvo', pelo João Köpke”, e o tom elogioso dado a ele, indiciam não só uma deferência ao intelectual 
que tem uma boa acolhida neste jornal, mas, sobretudo, a prática de leitura prevista para essa tradução ${ }^{17}$ : uma leitura "declamada" do poema pelo próprio tradutor.

Segundo a matéria, o tradutor é recebido "com enthusiastas palmas" por um "selecto público" (p. 2) interessado em sua audição, provavelmente composto pelos seus ex-alunos e familiares. Um público conhecedor da figura que Köpke construiu nos tempos em que estudou no Largo S. Francisco e em que foi professor e diretor de escolas para a elite paulista. ${ }^{18}$ Para esse público, João Köpke se mostra em tom de aparente humildade, situando o lugar de onde apresenta seu "despretensioso trabalho literário", talvez como estratégia para defender-se de possíveis críticas:

Penhora-me sobremodo a concessão que me fizestes uns, e a atenção que vos dignais prestar-me todos, para a leitura do despretensioso trabalho literário, que a vossa apreciação venho esta noite submeter. Sem que pertença ao grêmio fulguroso daqueles espíritos privilegiados, que na música do verso sabem fazer vibrar todas as notas do sentimento humano [...]. (Jornal O Estado de S. Paulo, 14 maio 1916, p. 2, grifos nossos).

Nessa fala introdutória, João Köpke, em um recurso retórico, chama atenção para a distinção entre os espíritos privilegiados (escritores e músicos) e ele, um homem ligado ao mundo escolar. De fato, a tradução de $O$ corvo, divulgada na última década de vida de Köpke, remete a um tempo em que, não exercendo mais o magistério, ele é, contudo, reconhecido como o "velho mestre" e um importante intelectual. Nesse período, dedica-se aos serviços como "official do $1^{\circ}$ Districto de Hypothecas”, no Rio de Janeiro, considerando que a criação de escolas ou a sua atuação como professor e diretor não lhe garantiram um sustento confortável para

17. As práticas de audição de poemas e de assistência a dramas, peças, óperas e filmes em espaços públicos parecem vigorosas nas primeiras décadas do século XX. Uma consulta à programação cultural divulgada nos jornais publicados, como por exemplo, em 04 de maio de 1916, no Estado de S. Paulo, facilmente identificamos a divulgação de inúmeras atrações artísticas: no mínimo duas sessões diárias (matiné e noturna), em dezesseis locais de espetáculos (cinematographos e teatros), em plena quinta-feira.

18. Uma rede de republicanos e abolicionistas, bacharéis do Largo S. Francisco como João Köpke, é responsável pela construção dessa imagem elogiosa, veiculando matérias sobre a qualidade de sua atuação no campo da publicação de cartilhas e de livros, defendendo-o das críticas vindas, principalmente, do campo educacional. Desse grupo, destacamos os responsáveis pelos seguintes periódicos: o grupo liderado por Manoel Ferraz de Campos Salles (1841-1913), Américo Brasiliense (1833-1896) e Francisco Rangel Pestana (1839-1903), que fundam o jornal A Província de São Paulo (04/o1/1875); Francisco Quirino dos Santos (1841-1886), que cria A Gazeta de Campinas; Júlio de Mesquita (1862-1927); proprietário de O Estado de S. Paulo (que antes da proclamação da República, tinha o nome de A Província de São Paulo) e da Revista do Brasil, periódico lançado para atender um público mais intelectualizado e ligado à literatura e às questões nacionais, como educação, por exemplo. 
sua família, vivendo, muitas vezes, da ajuda financeira de amigos reconhecedores de sua capacidade intelectual, da inovação de sua proposta pedagógica, do seu investimento pessoal no magistério, nunca questionados por seus pesquisadores (FERREIRA, 2017; MORTATTI, 2000; PANIZZOLO, 2006; SANTOS, 2013).

Três meses após a leitura da tradução de $O$ corvo no sarau paulistano, o texto foi publicado na Revista do Brasil, em dois números diferentes (v. 3, n. 1, 1916, p. 362-372; e v. 4, n. 1, 1917, p. 8o-86). Na tradução impressa, João Köpke se esmera para mostrar-se um competente conhecedor da produção e da crítica literárias de seu tempo, da obra a ser traduzida e do seu autor, assim como de outras traduções e apresentações feitas para o poema $O$ corvo, as quais ele vira ou de que já ouvira falar.

Orientado, talvez, pelos leitores previstos para esse periódico - apreciadores especializados, escritores e críticos de literatura -, Köpke, nessa tradução impressa, dedica-se a se apresentar à altura dos frequentadores legitimados desse ambiente. Opta, por exemplo, por colocar, lado a lado, o poema The raven, de Edgar Allan Poe (infelizmente, sem indicar a edição) e a sua tradução para ele. Uma opção que aponta, para o leitor, o modo operante da tradução empreendida por Köpke: suas escolhas, decisões, ajustes, dificuldades e impossibilidades. Uma opção que permite ao leitor não só comparar texto original e texto traduzido, como também sugere a intenção de demonstrar sua capacidade de traduzir o mais próximo possível da versão criada pelo autor original, uma "versão paraphrastica", como ele mesmo a define (KÖPKE, 1916, p. XX).

Também esmerando-se em mostrar-se competentemente "autorizado" para fazer tal tradução, ele inclui muitas e longas notas explicativas ao leitor (no rodapé da página), diversas citações de críticos e literatos como, por exemplo, James $\mathrm{H}$. Van Sickle ${ }^{19}$, ou diversos fragmentos comentados e retirados do artigo intitulado "Philosofia da composição", escrito por Edgar Allan Poe.

O referido artigo de Poe é adotado por João Köpke como o "guia" que orienta o processo de composição do original e de seu texto. Citando as palavras de Sickle:

Na realidade, porém, "O Corvo" não tem mysterio nenhum. O próprio Poe, num artigo intitulado "a Philosophia da Composiçao" explicou como o compoz - cuidadosamente como se constroi uma casa, pondo pedra sobre pedra com o projecto à vista desde o

19. James H. Van Sickle (1852-1926) fez uma extensa biografia sobre Edgar Poe, no $8^{\circ}$ volume da série Riverside Readers, na página 148. 
início. Parte delle é comedia, e assim deve ser lido. O todo é belleza. Nenhum conto que escreveu o autor tem um tecido mais logico. (KÖPKE, 1917, p. 369, grifo do autor).

Suas escolhas linguísticas são constantemente justificadas pelos seus comentários a respeito dos usos da linguagem (estribilho, metáforas, imagens poéticas, versificação etc.); da estrutura formal do texto (uma extensão breve, cerca de cem versos, estrutura lógica); da construção do enredo (local, personagens-amantes etc.); da prática de leitura indicada (para ser lido "de uma assentada" e ligada em parte ao gênero "comédia"). Uma tradução que, adotando o projeto previsto por Poe, não pode descuidar-se ainda do efeito desejado pelo poeta - emocionar o leitor, como ele exemplifica nos versos que concluem o poema, por exemplo: "tira o teu bico de meu coração e o teu vulto de sobre a minha porta. / Disse o corvo: 'Nunca mais'" (KÖPKE, 1917, p. 368), em que:

No que ahi fica exposto, não é nosso empenho justificar qualquer pretenção que tenhamos a haver feito obra que não desmereça do original: sim, só, deixar explicitos os fundamentos, que nos levaram a dar à nossa translação a forma sob a qual apparece, e que, a nosso ver e sentir, é a mais apropriada a produzir a impressão com que foi escolpo do poeta emocionar o leitor.

Além de apresentar-se como um intelectual familiarizado com a arte, conhecedor da produção literária e crítica em torno dos textos que elege para traduzir, João Köpke comenta outras traduções nacionais para The raven, como, por exemplo, a que fizera Machado de Assis, a quem "sobrava competencia e autoridade para intepretação mais acomodada à verossimelhança”" (KÖPKE, 1917, p. 82).

Dessa forma, a estratégia de erudição demonstrada por João Köpke vai compondo um sentido de legitimidade do próprio processo de construção de seu texto (totalmente conforme ao modo operante de Poe) e uma imagem de tradutor como grande conhecedor da língua e literatura inglesas; sensível a uma tradução além da "ideia contida em cada vocábulo" (KÖPKE, 1917, p. 82 ), para uma busca pela expressão dada pelo autor na apreensão de todo o verso e do contexto do poema.

No prefácio dessa tradução, Köpke vai compondo ainda a sua compreensão a respeito do que é arte, do que é literatura, destacando - com deferência - aspectos considerados próprios de uma obra-prima e que, como tradutor, ele deve conservar. Um aspecto, por exemplo, que é o de cuidar para que a apreciação universal reconheça 
o tom da tristeza como o tom mais conveniente e mais legítimo da beleza que "[...] leva invariavelmente, no seu supremo desenvolvimento, a alma sensível às lágrimas, sendo em consequência, a 'melancolia' o mais legítimo de todos os tons poéticos" (KÖPKE, 1916, p. 363). Um segundo aspecto é o de associar o belo da poesia ao "dom de escolher os mais bellos sons e combinal-os em musica perfeita" (KÖPKE, 1916, p. 363). Por último, o terceiro aspecto está ligado não só "à habilidade de esgrimir com as palavras" (KÖPKE, 1916, p. 368), mas também ao modo de recitá-lo, de interpretá-lo oralmente, de acordo com o gênero (literatura) proposto pelo autor.

Assim, para Köpke, uma tradução que preserve a obra-prima original não parece ligada apenas às palavras do texto em si, em sua forma literal. $O$ tradutor deve atentar-se para outros elementos envolvidos na produção da tradução: os efeitos que o poema deve provocar em seu leitor (levá-lo às lágrimas, a apreciar o Belo); os modos como o texto (em seus mais belos sons) chega aos seus leitores; a prática de leitura, que é a da declamação, citando Sickle: "Recitava o poeta [Poe] por vezes este extranho poema, e aquelles que o ouviram, falam de sua maneira cheio de enthusiasmo [...]" (KÖPKE, 1916, p. 363).

Nesse caso, Köpke chama a atenção também para as práticas de leitura/audição, indissoluvelmente ligadas ao poema e a serem consideradas pelo autor, pelo tradutor, pelo intérprete. Para quem traduz (em outra língua), para quem recita - em tom de conversa, encenando, declamando, lendo apoiado no texto escrito -, para quem aprecia o poema, a interpretação é imperfeita, porque não se restringe apenas ao entendimento do significado das palavras; é exigente, porque deve tocar o leitor-ouvinte "na inteligencia e no coração"; é "demonstração de praticabilidade do impossível”. (KÖPKE, 1916, p. 368). Daí seu esmero na tradução, a fim de lhe dar um estatuto à altura da qualidade da obra original, daí sua visão de composição do texto incorporar a literariedade; os efeitos a serem provocados no leitor; a musicalidade das palavras; a prática de declamação pelo próprio autor - modos de lidar com a produção de Köpke, conforme já vimos em Ferreira (2017).

\section{FinAlizANDO: APROXIMAÇÕES}

Considerando apenas esse corpus do nosso trabalho, algumas aproximações podem ser feitas em relação à atuação de João Köpke no campo da tradução. Aproximações que vão delineando uma coerência desse tradutor na escolha de 
uma língua estrangeira, de autores e obras contemporâneas a sua época, de uma temática literária, entre outros.

Uma primeira aproximação, por exemplo, é considerar a primeira publicação das obras "inspiradoras" das traduções de Köpke. Todas elas, A dama de Lyons (de 1838); The raven (de 1845); Evangeline, a tale of Acadie (de 1847); A bride's tragedy (de 1859) e Doctor Marigold's prescriptions (de 1865) se referem a livros publicados inicialmente em meados do século XIX. Um conjunto de obras traduzidas (conjunto esse que pode ser ampliado com livros evocados por Köpke nos documentos analisados) - que indica a circulação de publicações, na língua inglesa, na época.

$\mathrm{Na}$ escolha dos autores, diferentemente da força da cultura francesa, no século XIX (ABREU, 2013, 2014; WYLER, 2003), Köpke optou por cinco que originalmente foram traduzidos do inglês. Dois são estadunidenses: Edgar Allan Poe (18091849) e Henry Wadsworth Longfellow (1807-1882), e três são ingleses: Dinah Maria Mulock Craik (1826-1887), Edward L. Bulwer (1803-1873) e Charles Dickens (18121870). Uma outra aproximação: todos são autores de língua inglesa que viveram no século XIX, sendo que, com exceção de Poe, os demais ainda eram vivos quando Köpke nasceu. Uma opção vinculada a sua atividade como professor de inglês (embora o fosse também de francês e italiano), lembrado por alunos e ex-alunos.

Trata-se, enfim, de autores e obras que parecem ter conquistado os escritores, pois especialmente Evangeline e $O$ corvo tiveram publicações com mais de um tradutor, e seus autores são recorrentemente citados em depoimentos de letrados. É possível pensar que a oferta de outras traduções - que não as de João Köpke - tenha ocupado a preferência dos leitores, ou que um público seleto possa ter lido na língua original, considerando que Charles Dickens, Henry Longfellow, Allan Poe e Edward L. Bulwer são autores localizados em acervos de gabinetes de leitura, como mostram estudos de Schapochnick (1999) e Ramicelli (2016). Apenas Dinah Maria Mulock Craik parece fugir a esta regra, ao se apresentar desconhecida de João Köpke e dos leitores atentos ao folhetim publicado como de autoria de John Hallifax, ainda que ela seja atualmente reconhecida como escritora de best sellers, com edições de suas obras ainda disponíveis para o público leitor.

Também ele optou por traduzir apenas autores que foram reconhecidos pelos seus contemporâneos como ligados ao Romantismo, estética que se destacou em meados do século XIX no Brasil. Talvez pela sua sólida formação humanística (PANIZZOLO, 2006) ou porque era essa a tendência que se firmava nas obras que circulavam e eram compartilhadas com os seus colegas do Largo S. Francisco, engendradas no 
sentimento de nação e de um projeto de fortalecimentos de certos ideais republicanos, que tanto conquistaram os corações e pensamentos desses intelectuais.

Uma reincidência na tradução de autores "românticos", provavelmente, não só um gosto pessoal do tradutor, mas principalmente a aceitação do gênero pelos autores voltados a atender ao gosto dos leitores daquela época. Uma reincidência na temática romântica da dor causada pela separação dos amados.

Uma outra aproximação se faz pelo suporte de divulgação dessas traduções realizadas por João Köpke. Os periódicos impressos carregaram seus textos: $O$ corvo na Revista do Brasil; A tragédia de uma noiva e As receitas do doutor Marigold no jornal A Provincia de São Paulo. Mas também suas traduções migraram para outras linguagens e suportes, ganhando encenação (A morgadinha de Lyon) ou sendo oralizada pelo próprio Köpke $(O$ corvo). Suportes de textos à disposição de João Köpke, diretamente patrocinados pelo grupo de intelectuais com os quais ele se relacionou durante toda a vida.

Suas traduções nos mostram, em conjunto, um quadro um tanto diversificado quanto à dinamicidade da produção e da circulação de obras, em meados do século XIX: materializadas em jornal, livro, manuscrito, revista especializada, declamação oral; mobilizadas pelas práticas culturais da audição, leitura silenciosa, encenação; apreciadas em prosa e versos, de forma fragmentada, integral, na língua portuguesa ou em texto bilíngue; destinadas a leitores especializados, leitoras dos folhetins, frequentadores de espaços culturais, leitor-revisor do próprio texto - quer como atividade profissional, quer como atividade ligada ao cotidiano. Coerentemente, Köpke mostrou que as traduções, longe de serem textos abstratos, chegam a diferentes leitores, em suportes e práticas culturais diversos, em um século em que a leitura socializada é vista como aquela que ilustra a alma, forma mentes, torna os homens cidadãos. Mas também podem levar seus leitores às lágrimas, carregando-os pela musicalidade, pelo uso da palavra na medida e no lugar certos, mobilizadas pelas práticas de leitura.

\section{REFERÊNCIAS}

ABREU, Márcia. O gosto dos leitores - a recepção de romances como problema para a história literária. In: SALES, G. M. A. et al. Interpretação do texto, leitura do contexto. Rio de Janeiro: Letras; Capes, 2013. p. 167-187.

ABREU, Márcia (Org.) Romances em movimento. A circulação transatlântica dos impressos (17891914). Campinas: Editora Unicamp, 2016.

ACÁDIA. In: Grande Enciclopédia Larousse Cultural. Cidade: Editora, 1987. v. 1, p. 34. 
"Que ninguem supporá que eu ignore o nome do escriptor": João Köpke, o tradutor

A PROVINCIA DE SÃO PAULO. Tragédia de uma noiva, por Wilkie Collins, Trad. direto do inglez por João Köpke. $1^{\mathrm{a}}$ parte. São Paulo, p. 1, $1^{\mathrm{o}}$ abr. $1875 \mathrm{a}$. . Rectificação. São Paulo, 03 abr. 1875b.

BOURDIEU, Pierre. Leitura: uma prática cultural - debate entre P. Bourdieu e R. Chartier. In: CHARTIER, R. Práticas de Leitura. SP: Estação Liberdade, 1996. p. 229-253.

CAMPOS, Aline C. de A.; RAMOS, Ana Rosa N. Questões identitárias no Canadá francófono: o caso da Acádia. Revista Interfaces Brasil/Canadá. Rio Grande, v. 9, n. 10, p. 153-164, 2009. Disponível em: <http://www.revistabecan.com.br/arquivos/1259533771>. Acesso em: 15 set. 2012.

CANDIDO, A. Formação da literatura brasileira: momentos decisivos. 5. ed. Belo Horizonte: Editora Itatiaia; São Paulo: Editora da Universidade de São Paulo, 1975.

CHARTIER, Roger. A história cultural: entre práticas e representações. Lisboa: Difel, 1990.

CRAIK, Dinah M. M. A bride's tragedy. In: . Domestic stories. Londres: Smith, Elder \& Co., 1867, p. 303-333. Exemplar digitalizado por Google, original da Indiana University. Disponível em: <http://onlinebooks.library.upenn.edu/webbin/book/lookupname?key=Craik\%2C\%20 Dinah\%2oMaria\%2oMulock\%2C\%201826-1887>. Acesso em: 20 jul. 2017.

DIÁRIO DE SÃO PAULO. Nota: “Fomos obsequiados com um exemplar da Morgadinha de Lyon...”. São Paulo, p. 3, 20 ago. 1874. . Errata. São Paulo, p. 2, 02 abr. 1875.

DICKENS, Charles. Doctor Marigold's prescriptions. The extra Christmas number of all the year round. London: Chapman \& Hall, Christmas, 1865. (cópia digitalizada por University of California Libraries). Disponível em: <https://archive.org/stream/doctormarigoldspoodickrich\#page/ no/mode/2up >. Acesso em: 22 jul. 2017.

DÓRIA, Franklin. Evangeline. Rio de Janeiro: Laemmert, 1874. Disponível em: <https://ihgb.org. $\mathrm{br} /$ pesquisa/biblioteca/item/19148-evangelina-h-w-longfellow-traduzida-do-original-inglezpor-franklin-doria.html>. Acesso em: 20 jul. 2017.

FERREIRA, Norma S. A. As cartilhas de João Köpke para o ensino da leitura. Revista Brasileira de Alfabetização, Vitória-ES, v. 1, n. 1, p. 155-176, jan./jun. 2015.

. Um estudo sobre "Versos para os pequeninos", manuscrito de João Köpke. Campinas-SP: Mercado de Letras, 2017. Apoio FAPESP.

GAZETA DE CAMPINAS. Drama. A morgadinha de Lyon. Campinas, ano VI, [s.p.], o8 nov. 1874. HALLEWELL, Laurence. O livro no Brasil: sua história. Tradução de Maria da Penha Villalobos e Lólio Lourenço de Oliveira. 2. ed. São Paulo: Edusp, 2005.

HILSDORF, Maria Lúcia. S. 1986. Francisco Rangel Pestana: jornalista, político, educador. Tese (Doutorado em Educação) - Faculdade de Educação, Universidade de São Paulo, São Paulo, SP, 1986. KÖPKE, João. Méthodo Rapido para aprender a ler. Rio de Janeiro: Laemmert, 1874.

. Tragédia de uma noiva de Dinah Maria Mulock Craik - $1^{\mathrm{a}}$ Parte. Traduzido do inglês por J. Kopke. A Província de São Paulo, São Paulo, p. 1, o1 abr. 1875a.

. "As receitas do doutor Marigold", de Charles Dickens. Traduzido do inglês por J. Köpke.

A Provincia de São Paulo, São Paulo, abril/maio 1875b. 
. Carta de João Köpke dirigida a José Maria Lisboa quando da sua vinda como promotor de justiça para Faxina. 1875c. Disponível em: http://www.ihggi.org.br/conteudo/acervo/upload_ documentoshistoricos/Cartade JoaoKopke_3.pdf Acesso em: 05 mar. 2011.

. O corvo. Revista do Brasil: publicação mensal de Sciencia, Letras, Artes, História e Actualidades, São Paulo, v. 3, n. 1, p. 362-385, set./dez. 1916.

. O corvo. Revista do Brasil: publicação mensal de Sciencia, Letras, Artes, História e Actualidades. São Paulo, v. 4, n. 2, p. 70-114, jan./abr. 1917.

. Cartas de João Köpke à Radio Sociedade do Rio de Janeiro: 26 nov. 1924; 12 nov. 1924;

13 abr. 1924; 3 abr. 1926. Disponível em: <www.fiocruz/br/radiosociedade/med.Ao3/o874>. Acesso em: jan. 2013.

. Carta de João Köpke ao seu neto, Maurício Goulart. Arquivo IEB USP, caixa 19 - CPJ mg 034. São Paulo: Instituto de Estudos Brasileiros, Universidade de São Paulo.

. [?]. O casamento de Panurgo. [s.n.t.], 27 p. Datilografado. Trabalho não publicado. (Acervo da família Köpke).

. [?]. O pássaro dourado: uma peça em seis atos. [s.n.t.]. 49 p. Datilografado. Trabalho não publicado. (Acervo da família Köpke).

. Versos para os pequeninos: pelo director do Instituto Henrique Köpke. [s.n.t.]. p. 54. Trabalho não publicado. (Acervo da família Köpke).

KÖPKE, João; KÖPKE, Winckelmann. Evangeline, um conto de amor. Tradução de Henrique Wadswowth Longfellow. [s.n.t.]. 51 p. Datilografado. Trabalho não publicado. (Acervo da família Köpke).

LYTTON, Edward Bulwer. The lady of Lyons, or Love and pride. [1938]. Projeto Gutenberg, 2008. Disponível em: <http://www.gutenberg.org/ebooks/2461?msg=welcome_stranger>. Acesso em: 16 maio. 2017.

LOBO, Américo. Evangeline. Rio de Janeiro: Typografia G. Leuzinger e Filhos, 1884.

LONGFELLOW, Henry. Evangeline. New York: Imprint Boston, 1921. (1883, microfilme).

MAZIERO, M. Dores S. Arnaldo de Oliveira Barreto e a Biblioteca Infantil Melhoramentos (1915-1925): Histórias de ternura para mãos pequeninas. 2015. Tese (Doutorado em Educação)- Faculdade de Educação, Universidade Estadual de Campinas, Campinas, SP, 2015.

MENESES, João G. de C. Discurso de posse do acadêmico João Gualberto de Carvalho Meneses. Academia Paulista de Educação, São Paulo, 21 out. 1980. Disponível em: <http://www.apedu.org. $\mathrm{br} /$ home/index.php?option=com_content\&view=article\&id=129:discurso-de-saudacao-aoacademico-moacyr-expedito-marret-vaz-guimaraes $\&$ catid $=10$ : discursos $\& I t e m i d=171>$. Acesso em: 10 out. 2012.

MODENEZ, Julio C. A circulação de traduções francesas no Rio de Janeiro (1860-1865). Cultura \& Tradução, João Pessoa, v. 3, n. 1, p. 223-232, 2014.

MORTATTI, Maria do Rosário L. Os sentidos da alfabetização: São Paulo - 1876/1994. São Paulo: Editora Unesp; Brasília: MEC/Inep/Comped, 2000.

O ESTADO DE S. PAULO. A leitura de "O Corvo", pelo João Köpke. ARTES E ARTISTAS - Sociedade de Cultura, Artes e Letras. São Paulo, p. 2, 14 maio 1916. 
"Que ninguem supporá que eu ignore o nome do escriptor": João Köpke, o tradutor

PANIZZOLO, Cláudia. João Köpke e a escola republicana: escritor de leitura, escritor da modernidade. Tese (Doutorado em Educação) - Programa de Pós-Graduação em História, Política e Sociedade, Pontifícia Universidade Católica de São Paulo, São Paulo-SP, 2006.

RIO, João do. Momento Literário. Rio de Janeiro: Fundação Biblioteca Nacional. Dep. Nacional do Livro, 1994.

RAMICELLI, M. Eulália. Ficção britânica no extremo sul do Brasil: o acervo oitocentista da Biblioteca Rio-Grandense. In: ABREU, Márcia (Org.). Romances em movimento. A circulação transatlântica dos impressos (1789-1914). Campinas: Editora Unicamp, 2016. p. 93-119.

SANTOS, Maria Lygia C. K. 2013. Lendo com Hilda: João Köpke - 1902. Tese (Doutorado em Educação)- Faculdade de Educação, Universidade Estadual de Campinas, Campinas-SP, 2013.

SHAPOCHNIK, Nelson. 1999. Os jardins das delícias: gabinetes literários, bibliotecas e figurações da leitura na corte imperial. Tese (Doutorado)- Faculdade de Filosofia, Letras e Ciências Humanas, Universidade de São Paulo, São Paulo, 1999.

VASCONCELOS, Sandra G. Circuitos e travessias: O caso de "A Família Elliot”. In: ABREU, Márcia (Org.). Romances em movimento. A circulação transatlântica dos impressos (1789-1914). Campinas: Editora Unicamp, 2016. p. 135-157.

WYLER, Lia C.A. 1995. A tradução no Brasil: ofício invisível de incorporar o outro. Dissertação (Mestrado em Comunicação e Cultura) - Universidade Federal do Rio de Janeiro, Rio de Janeiro, 1995.

. Línguas, poetas e bacharéis: uma crônica da tradução no Brasil. Rio de Janeiro: Rocco, 2003.

\section{SObRe AS AUTORAS}

Norma Sandra de Almeida Ferreira é Professora Livre Docente e coordenadora do grupo de pesquisa Alfabetização, Leitura e Escrita-ALLE da Faculdade de Educação, Universidade Estadual de Campinas. Atua na área "Conhecimento e linguagem”. É Pós-doutora (Universidade de Algarve - Portugal), Doutora e Mestre em Educação (Universidade Estadual de Campinas). Atualmente é Professora Associada/Colaboradora da Universidade Estadual de Campinas. Tem experiência na área de Educação, com ênfase em: leitura, escrita, literatura infantil e alfabetização.

E-mail: normasandra@yahoo.com.br.

Maria das Dores Soares Maziero é graduada em Letras (Pontifícia Universidade Católica de Campinas), tem Mestrado e Doutorado em Educação (Universidade Estadual de Campinas). Atualmente é professora da Faculdade de Paulínia e pesquisadora do Grupo de pesquisa Alfabetização, Leitura e Escrita - ALLE (Universidade Estadual de Campinas). Tem experiência na área de Educação, 
com ênfase em leitura, escrita, literatura infantil e alfabetização, com pesquisa nos seguintes temas: história do livro infantil no Brasil e literatura infantil no final do século XIX e início do XX.

E-mail: s.maziero@uol.com.br.

Recebido em 31 de março de 2017 e aprovado em 26 de abril de 2017. 